\title{
FINCAS DISPERSAS, COTOS REDONDOS Y CAMBIO ECONOMICO EN ESPAÑA
}

\author{
RICHARD HERR \\ Universidad de California (Berkeley)
}

Los grandes de España son famosos por su despreocupación económica. Leer la historia económica de España es oír repetidamente" el canto lúgubre de que sus grandes terratenientes, que disfrutaban de magníficas rentas, sin importarles un bledo el estado de sus propiedades o el sufrimiento de sus campesinos («no importar un bledo» es una expresión hecha a medida de los grandes de España), han sido responsables durante siglos de la baja productividad de la agricultura española y de la pobreza del campo. Una de las razones que se citan frecuentemente para explicar el abandono en que dejaban sus tierras es que las disposiciones institucionales por las que tenían su propiedad hacían que sus fincas estuvieran dispersas por toda España. Al no poder vivir más que en una pequeña parte de sus propiedades, renunciaban a todo intento de ser propietarios residentes y huían a Madrid, centro de la Corte real y de las relaciones sociales con sus iguales.

Los duques de Alba o, en el siglo xviII, generalmente las duquesas de Alba, eran señores de una gran parte de la provincia de Salamanca, en la que también tenían fincas, así como los mayores hacendados en cinco lugares de Andalucía y señores en otros nueve (1). El duque de Medinaceli era el mayor hacendado en veinticuatro lugares situados en tres de las cuatro provincias de Andalucía y tenía otras fincas no menos importantes en Cataluña y otras partes de España. Sólo administrar estas vastas propiedades mantenía ocupados a treinta contables en Madrid (2). El duque de Medina Sidonia, el duque del Infantado, el duque de Osuna y muchos grandes más modestos y otros nobles seguían la misma pauta en mayor o menor grado (3). Según la explicación generalmente aceptada, la práctica de las fincas dispersas y las

(1) España dividida en provincias $e$ intendencias $y$ subdividida en partidos... (Madrid, Imprenta Real, 1789), vol. I (el "Nomenclator de Floridablanca"), y Miguel Artola y otros. El latifundio: propiedad y explotación, ss. XVII-XX (Madrid, Servicio de Publicaciones Agrarias, 1978), 42 y 54.

(2) Ibid., y Richard HerR, España y la revolución del siglo XVIII (Madrid, Aguilar, 1964), 80.

(3) Véase e. g., Artola, 32-48 y mapa 3. 
jurisdicciones señoriales no respondía a ninguna planificación económica ni siquiera irracional. Se puede explicar en gran parte por el mayorazgo, la institución del vínculo legal de las posesiones familiares, que se creó con el propósito principal de proteger a las futuras generaciones nobles de los estragos de los herederos manirrotos y, por tanto, para impedir el declive económico de la nobleza de España (4). Cuando dos herederos de un mayorazgo se casaban, sus propiedades pasaban juntas a las generaciones posteriores, más o menos de la misma forma en que Carlos $V$ unió su vasto imperio en toda Europa, con resultados no muy diferentes desde el punto de vista estructural. Si las alianzas matrimoniales reales produjeron monarquías dinásticas, los matrimonios aristocráticos crearon lo que podría llamarse propiedad dinástica de la tierra.

En el siglo xvirr, los reformistas se quejaban de que esas disposiciones producían resultados económicamente ineficientes. En 1798, Carlos IV decretó la subasta de propiedades pertenecientes a ciertas fundaciones religiosas y obras pías con el fin de utilizar los ingresos para reducir el déficit real. Esta legislación constituyó el primer asalto deliberado a la propiedad vinculada, si bien es cierto que eclesiástica, no seglar, y en este artículo nos ocuparemos de ella detenidamente (5). Sin embargo, ahora interesa señalar que cinco años más tarde, en 1803, Carlos IV autorizó a los propietarios de mayorazgos y otros vínculos legos a vender sus propiedades más lejanas con el fin de comprar bienes eclesiásticos desamortizados más próximos a sus fincas principales, para que, como decía su decreto, "al paso que promueva la venta de bienes de establecimientos píos, facilite a los poseedores de Mayorazgos y otros Vínculos la reunión de las fincas dispersas de su pertenencia, en que tienen tanto interés por el ahorro de gastos de administración, y por la ventaja de poder dedicarse a procurar por sí mismos todas las mejoras de que sean susceptibles y de que debe resultar a la causa pública el grande beneficio del adelantamiento y fomento general de la agricultura» (6).

No recuerdo que nadie haya comparado nunca esta inclinación de los aristócratas a dispersar sus propiedades con la característica aún mejor conocida de la agricultura de campos abiertos (open fields) del norte de Europa, en la que cada familia campesina trabajaba grupos dispersos de parcelas alargadas (strips). Su ineficacia también ha sido denunciada frecuente y abierta-

(4) Esta es la explicación que ofrece Raymond Carr en su capitulo "Spain", en A. Goodwin, ed., The European Nobility in the Eighteenth Century (Londres, Adam and Charles Black, 1953), 48-49. Es un lugar común.

(5) Véase Richard HERr, "Hacia el derrumbe del Antiguo Régimen: crisis fiscal y desamortización bajo Carlos IV", Moneda y Crédito, 118 (septiembre 1971). 39-100.

(6) Real cédula 6375, 3-II-03, Archivo Histórico Nacional, Madrid, Hacienda, libro 8555 , fols. $38-50$; véase p. 45 . 
mente, tanto por reformistas agrícolas del siglo xvirI, como Arthur Young, como por historiadores económicos posteriores. La dispersión de las parcelas, incluso en los lugares en los que las leyes y costumbres locales podrían haber permitido el cerramiento, suponía una pérdida de tiempo para los campesinos y sus yuntas en innecesarias idas y venidas a través del campo y aumentaba el coste del vallado hasta alcanzar niveles prohibitivos. Jan de Vries ha comparado las ventajas económicas de las granjas integradas de familias campesinas con las desventajas de las explotaciones formadas por parcelas dispersas. En contraste con los vínculos aristocráticos, a los que se acusa de concentrar unas propiedades excesivamente grandes y distantes, el sistema de tierras dispersas, según De Vries, llevó a una distribución incontrolada de las parcelas entre sus herederos y dio lugar a propiedades individuales que no podian utilizar todo el trabajo de sus propietarios ni mantener a sus familias (7). Los cerramientos parlamentarios, como sabemos, reorganizaron las parcelas y yugadas de los pueblos ingleses en fincas compactas y eficientes que se podían vallar y cultivar utilizando sistemas rotatorios más productivos. Al movimiento de cerramientos (enclosure movement) se le ha atribuido, en gran parte, el mérito de permitir aumentar la producción agrícola que contribuyó a hacer posible la revolución industrial inglesa. La agricultura de open field de la gran llanura del norte de Francia también tenía yugadas dispersas. Aunque Francia no fue testigo de ningún movimiento de cerramientos parecido, sus fisiócratas denunciaron esa práctica y los señores y otros grandes propietarios lucharon por crear unas fincas integradas, para recrear las heredades señoriales medievales tal y como ellos las entendían. Marc Bloch ha descrito su progresivo, pero inexorable, progreso, frenado finalmente por la legislación de la Revolución (8).

En el mundo mediterráneo, debido probablemente a que se utilizaba un! arado más sencillo - sin ruedas-, las tierras de los pueblos se dividieron en quiñones irregulares y no en parcelas alargadas, pero el grado de disper-; sión fue tan grande como en el Norte. El catastro del marqués de la Ensenada y los registros de la venta de propiedades eclesiásticas en la desamortización de Carlos IV muestran que en la provincia de Salamanca la forma más corriente de distribución de la tierra en los pueblos dedicados a la producción de cereales eran pequeñas parcelas de sembradura de secano distribuidas a lo largo de grandes hojas. Una explotación consistía en una serie de parcelas, situadas en diferentes partes del término municipal. Esta pauta parece que fue general en la meseta Norte y en gran parte de la Sur, donde

(7) Jan DE VRIEs, The Dutch Rural Economy in the Golden Age, 1500-1700 (New Haven, Yale University Press, 1974), 1-17.

(8) Marc Bloch, Les caractères originaux de l'histoire rurale française (París, Armand Colin, 1964), cap. 4 (edición francesa original, 1931). 
los cereales constituían el principal producto; pero no conozco ningún estudio sobre las prácticas españolas del pasado, aunque los reformistas rurales y los antropólogos sociales les han prestado mucha atención en el siglo xx.

Se han dedicado numerosos trabajos históricos a exponer las teorías sobre las razones por las cuales los campesinos adoptaron el open field y las franjas dispersas, sobre todo en relación con el caso inglés. Los estudiosos se han esforzado en defender explicaciones tan diferentes como que respondían al deseo de los campesinos de igualdad social y económica, derivado del espíritu igualitario que llevaban consigo los invasores procedentes de los bosques de Alemania, o que fue el invento del arado de ruedas el que obligó a adoptar el sistema, o que el crecimiento de la población y las subdivisiones consecutivas entre los herederos produjeron innumerables y diminutas explotaciones (9). Uno de los estudios que han dado un giro a los debates ha sido el de Donald McCloskey, el cual, en lugar de analizar por qué surgieron las franjas, se interesa, más bien, por las causas por las que duraron tanto después de que el desarrollo de los mercados de productos agrícolas demostrara las ventajas de la consolidación. Este autor concluye que los campesinos preferían las parcelas dispersas porque reducían el riesgo de los desastres naturales y las consiguientes malas cosechas. La dispersión era una respuesta económicamente racional a un sistema que todavía no conocía el seguro de las cosechas (10). Su argumento no se ha aceptado universalmente, pero convendrá tenerlo en cuenta a medida que avancemos en nuestro razonamiento. Hace cincuenta años, Marc Bloch llegó a una conclusión bastante parecida en relación con la pauta de franjas dispersas de Francia: «Dispersando las posesiones, se creía igualar las oportunidades; se permitía que todos los habitantes participaran en diferentes tipos de suelo; todo el mundo tenía la esperanza de no sucumbir jamás totalmente a los diversos desastres naturales o humanos - granizos, enfermedades de las plantas, devastaciones- que pudieran afectar a un término sin destruirlo totalmente» (11).

Así, pues, la dispersión de las propiedades existía en ambos extremos de la escala social y económica. Tanto los ignorantes campesinos como los despreocupados grandes han sido acusados por los historiadores posteriores de frenar el crecimiento económico. Ninguno de estos grupos constituye el objeto

(9) Puede encontrarse un buen resumen de las cuestiones y presentación de las diferentes posturas en el debate sostenido en Past \& Present: Joan THIRsk, "The Common Fields", 29 (diciembre 1964), 3-25; J. Z. Trrow, "Medieval England and the Open-Field System", 32 (diciembre 1965), 86-102; THIRsK, "The Origin of the Common Fields", 33 (abril 1966), 142-147, y Robert A. Dodgshon, "The Landholding Foundations of the Open-Field System", 67 (mayo 1975), 3-29.

(10) Donald N. McCloskey, "The Persistence of the English Common Fields", en William N. PArker y Eric L. Jones (eds.), European Peasants and Their Markets (Princeton, Princeton University Press, 1975), 73-119.

(11) Bloch, I, 56. 
de este estudio, pero las características de sus prácticas en la propiedad y uso de las tierras proporcionan una base conceptual para nuestro estudio. En el resto del artículo, expondré mis hallazgos referentes a la desamortización de las propiedades eclesiásticas llevada a cabo bajo el reinado de Carlos IV, a la que me referí antes (12).

Una gran cantidad de propiedades eclesiásticas cambió de manos en esta desamortización. He estimado que ésta afectó a alrededor de un sexta parte de las propiedades controladas por instituciones religiosas y pías, que fueron adquiridas por todo tipo de personas, desde campesinos hasta grandes, si bien fueron los estratos sociales intermedios los que más compraron. He estudiado lo que ocurrió en dos provincias, Salamanca y Jaén (13) (véase el mapa 1). En Salamanca, se vendió el 20 por 100 de las propiedades eclesiás-

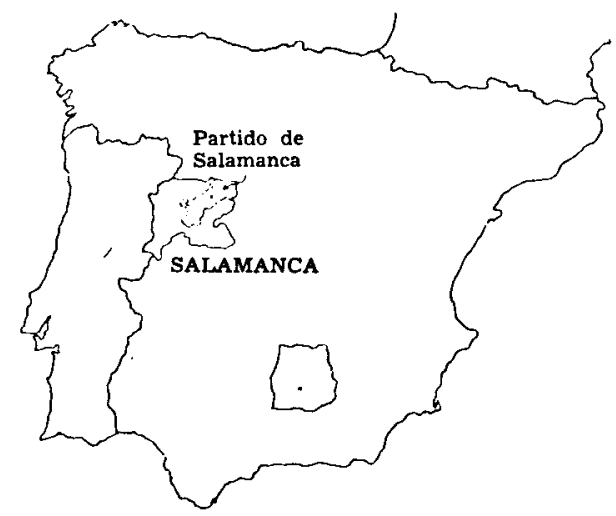

MAPA 1

ticas, es decir, el 7 por 100 de toda la tierra de la provincia; en Jaén, las cifras son 16 y 5 por 100 (14). Como éstas son medias provinciales, en algunas áreas la proporción fue, evidentemente, mayor.

Además de llenar las arcas reales, el principal objetivo de la desamortización fue reformar la propiedad de la tierra, sustituir la propiedad eclesiástica y las vinculaciones por la propiedad privada y el libre comercio. Estas innovaciones, que eran centrales en las doctrinas económicas clásicas, rompe-

(12) La información original que se presenta en el resto de este artículo procede de un libro que estoy escribiendo, y no toda irá citada en las notas a pie de página.

(13) Los hallazgos preliminares se encuentran en $\mathrm{mi}$ artículo "Hacia el derrumbe del Antiguo Régimen" (véase nota 5).

(14) Estas cifras representan la proporción del valor de las cosechas totales, no del área, debido a que la fuente existente (el catastro de la Ensenada) proporciona la primera cifra y tiene más sentido desde el punto de vista económico (ibidem, cuadros 2 y 3 ). 
rían las ataduras que limitaban el crecimiento agrícola; al menos eso era lo que creían los reformistas, de los cuales el más destacado fue Gaspar Melchor de Jovellanos, la principal figura intelectual de la Ilustración española. Podemos juzgar el grado en que la desamortización cumplió sus objetivos examinando la pauta de adquisiciones realizadas por algunos de los compradores más importantes.

La ciudad de Salamanca se encuentra en el centro de una rica llanura a la que en el siglo xviri dominaba política y económicamente. En ella las propiedades rurales importantes eran de dos tipos. Uno consistía en grupos de pequeñas parcelas de cultivo en régimen de open field, como las que hemos descrito antes. Muchas pertenecían a terratenientes ausentes o a institunente pequeña o nula, que se encontraban fuera de la jurisdicción de los pueblos a cambio del pago de cantidades convenidas de cereales y otras cosechas. El otro tipo consistía en grandes explotaciones con una población permanente pequeña o nula, que se encontraba fuera de la jurisdicción de los pueblos adyacentes, conocidas como despoblados o alquerías. Si pertenecían en su totalidad a un único dueño, ya fuera un particular, ya una institución, ya varios particulares de forma compartida, se llamaban términos redondos o cotos redondos. Generalmente, incluían una elevada proporción de pastos y se alquilaban mediante arrendamientos a corto plazo cuyo pago se realizaba tanto en grano como en dinero. Los propietarios dejaban la administración de las explotaciones a los arrendatarios.

La mayor parte del grano que recibían los propietarios como renta, bien de las parcelas arables, bien de los términos redondos, la vendían en el mercado a los precios vigentes, que a finales del siglo xvirI subieron de forma acusada. De los dos tipos de propiedad, los términos redondos parece que eran los más propicios al crecimiento económico. Al tratarse de grandes explotaciones libres del control de cualquier núcleo de población, eran susceptibles a la innovación y sus arrendatarios solían ser hombres con algún capital en herramientas y ganado. Era menos fácil que hubiera iniciativas individuales en las pequeñas parcelas dispersas, que tenían que seguir las rotaciones de las cosechas de los campos en los que estaban situadas.

Don Francisco Alonso y Moral era un comerciante de grano y cueros de la ciudad de Salamanca. En sus relaciones con los campesinos solía adelantar dinero, que debía serle devuelto en efectivo o en grano en la siguiente cosecha, por lo que comerciaba a futuro. No le importaba aprovechar una mala cosecha para conseguir de los campesinos contratos favorables. También administraba las fincas de algunos propietarios de mayorazgos (15). Cuando

(15) La mayor parte de la información sobre las actividades comerciales de Alonso y Moral proceden de las escrituras de Francisco Bellido, Archivo Histórico Provincial de Salamanca (AHPS), Protocolos 5908, 5909, 5913 (1798-1800, 1803). 
llegó la desamortización, pudo aprovecharse de ella, al estar familiarizado con el funcionamiento de la economía agrícola y disponer de capital. Se convirtió en uno de los mayores compradores de la provincia, adquiriendo en total cerca de mil parcelas de sembradura de secano y veinticinco prados, es decir, 600 ó 700 hectáreas de tierra de trigo candeal y pastos para las yuntas correspondientes, suficiente tierra para albergar un pueblo de buen tamaño con unos treinta vecinos dedicados a la agricultura, más otros dedicados a ocupaciones complementarias (16).

No pudo comprar grandes bloques de tierra, pues ésta era poseída en forma de grupos de pequeñas parcelas dispersas, pero se especializó en tierras arables y realizó sus compras en una región limitada de la rica llanura de Armuña, situada al norte de la ciudad. Casi todas sus parcelas se encontraban dentro de un círculo de veinte kilómetros de diámetro, dentro del cual se concentró en determinados lugares y no adquirió nada en otros (véase el mapa 2). Sólo hizo dos compras que no se ajustaron a esta pauta. Una fue

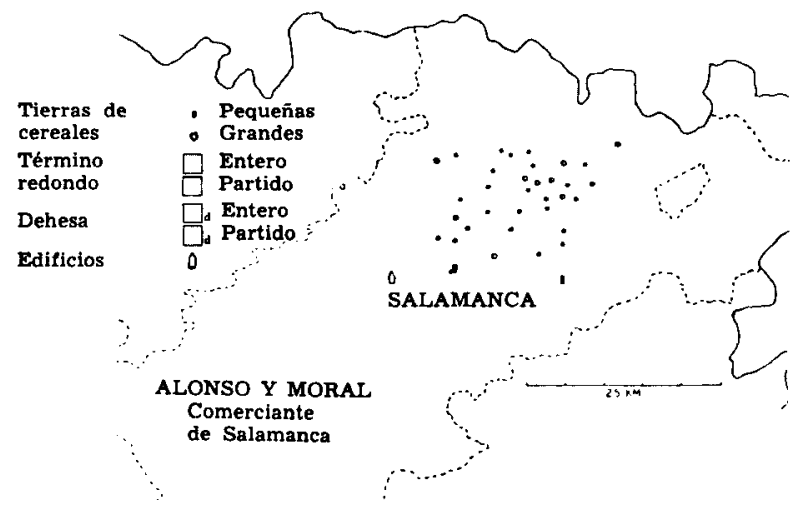

MAPA 2

una «casa con panera y demás oficinas» situada a ocho kilómetros al oeste de la ciudad, fuera del círculo, y que pensaría dedicar a sus negocios, independientemente de sus nuevas propiedades. La otra excepción fue una porción de un término redondo situado al sudeste de Salamanca, que adquirió justo

(16) Las compras de Alonso y Moral se encuentran en AHPS, Contaduria de Hipotecas, Libros 850-856 (Partido de Salamanca, 1791-1807). Las compras que no aparecen aquí se encuentran en los registros notariales de Juan Manuel López Fando, 1799-1807 (Archivo Histórico Provincial de Madrid), que recogía la mayor parte de las ventas de toda España. Esto también ocurre en el caso de los demás compradores de Salamanca, descritos más adelante. Véase mi artículo "Hacia el derrumbe del Antiguo Régimen", 56-57, para más detalles. 
antes de que cesaran las ventas. Fue parte de una venta que incluía tierra de dos de sus lugares y fue su única adquisición de una gran finca. Don Francisco no quería tratar con grandes agricultores arrendatarios; prefería centrarse en su negocio establecido como comerciante de granos y arrendar parcelas arables a campesinos a cambio de buen trigo candeal, lo que le permitía convertir en un dineral sus préstamos, si se presentaba la ocasión. Era un hombre de negocios que conocía las ventajas de la especialización.

Don Francisco conocía el terreno mejor que el abogado don Cosme Trespalacios, residente en Madrid, que realizó doce compras en la provincia de Salamanca en los primeros años de la desamortización, después de lo cual se mudó a esta ciudad y realizó otras siete. Al igual que Alonso y Moral, prefería los grupos de parcelas arables que podía arrendar y escogió unas 600 parcelas y 19 prados; pero no concentró sus adquisiciones tanto como don Francisco Alonso; los lugares en los que compró más no estaban cerca unos de otros. Entre sus adquisiciones también había un término redondo distante de sus pueblos. No tenía unos objetivos tan claros como Alonso y Moral (véase el mapa 3).

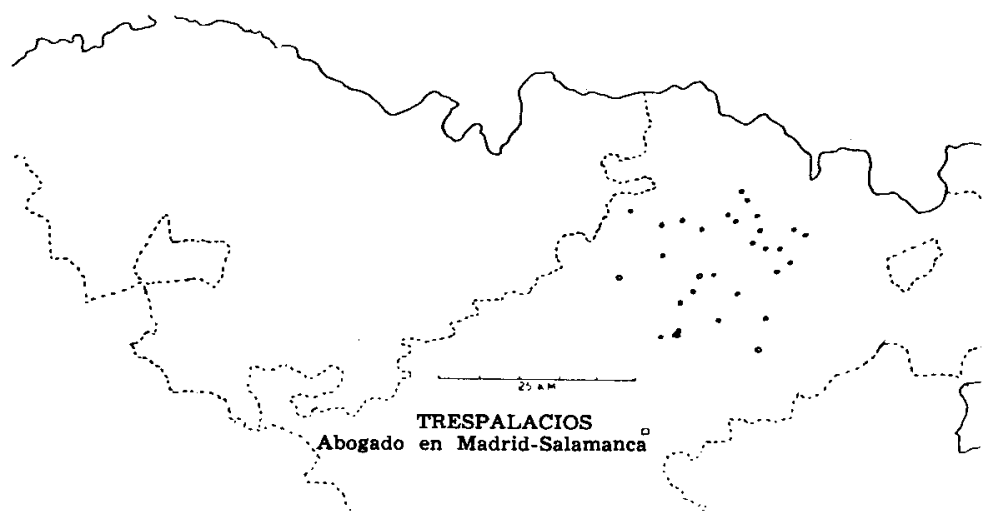

MAPA 3

La compra por Trespalacios de un término redondo sigue, de hecho, un enfoque diferente evidente entre los compradores que invertían en estas grandes propiedades, los cuales preferían comprar en localidades muy diferentes. Así lo atestigua el ejemplo del clérigo don Segundo Sánchez de Onís, que fue quien gastó más dinero de todos los compradores de la provincia. Adquirió tres términos redondos en su integridad, situados en tres partidos diferentes de la provincia, y dos grandes dehesas, una de ellas fuera de la provincia, así como cinco grupos de campos arables. Sus propiedades estaban situa- 
das en una extensión de 70 kilómetros de Este a Oeste y, quizá, 50 de Norte a Sur, si es que no realizó otras compras fuera de la provincia, cosa que mis fuentes no revelan (mapa 4 ).

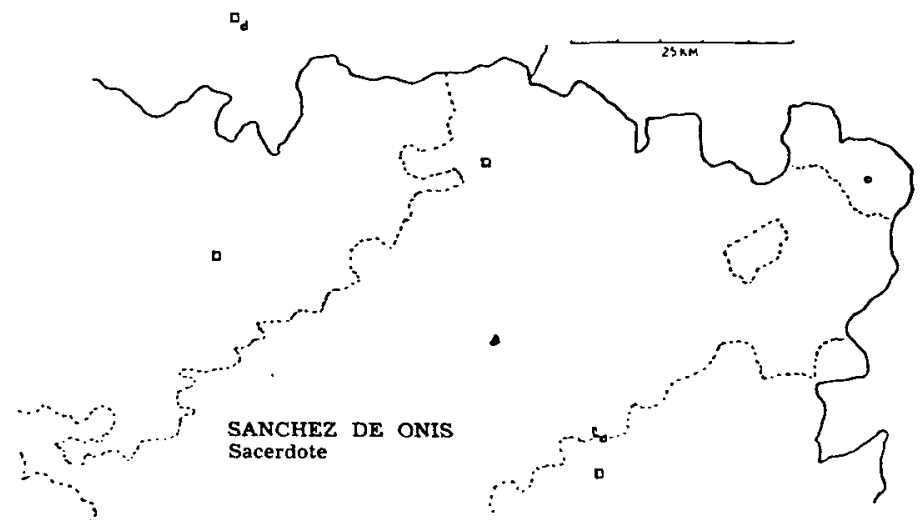

MAPA 4

Esta pauta fue seguida por personas muy diferentes. Don Antonio Reyrruard, miembro del gremio y claustro de la Universidad, compró un término redondo, campos arables en cuatro lugares y una cuarta parte de una dehesa, formando un triángulo todo ello de unos 40 por 30 kilómetros aproximadamente, con Salamanca en el centro (mapa 5). Don Francisco Sánchez

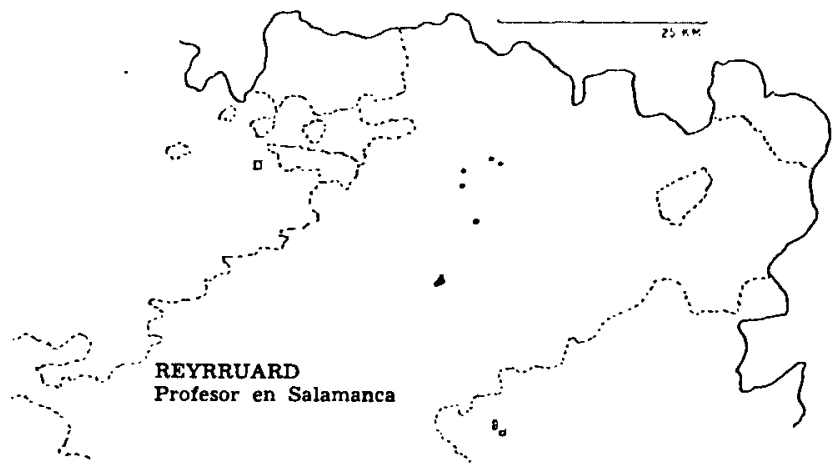

MAPA 5

García puede que viviera en la parte Oeste de la provincia, que fue donde realizó sus adquisiciones. Compró una quinta parte de un término redondo y parcelas arables en diez lugares, en una extensión de 65 kilómetros de 
Este a Oeste y 35 de Norte a Sur (mapa 6). Un comerciante de Bilbao, don Martín de Ganá, adquirió algunas parcelas de grano en siete lugares situados al norte, este, sur y oeste de la ciudad de Salamanca, una casa y más parcelas dentro de los límites de la ciudad, y un término redondo, todo el lugar

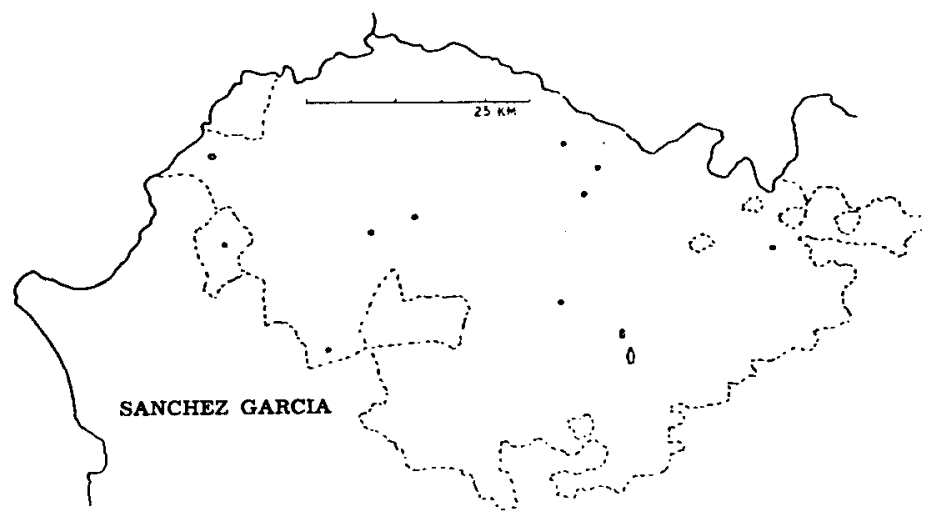

MAPA 6

de Vidola, con cerca de 300 habitantes, situado a 75 kilómetros al Oeste, cerca de Portugal (mapa 7).

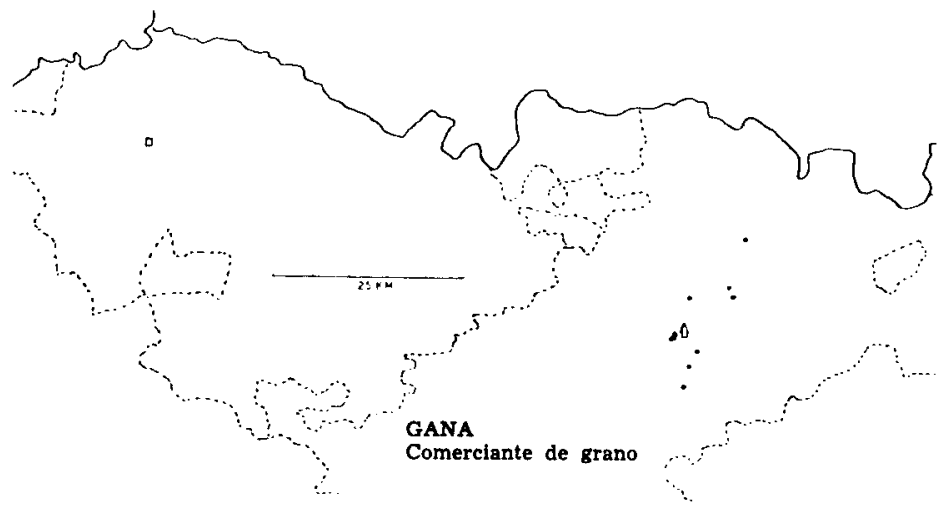

MAPA 7

Estos compradores dispersaban ampliamente sus propiedades, comprando tanto parcelas arables como grandes fincas dedicadas en parte a la ganadería. Sus operaciones eran la práctica corriente entre los compradores que tenían mucho dinero. A diferencia de Alonso y Moral, el astuto comerciante de granos, la mayoría de los inversores ricos buscaban la diversidad, no la homogeneidad y, especialmente, la diversidad geográfica. En su juego del Palé (Monopoly), preferían una propiedad de cada color a tres de un mismo tipo. 
Su estrategia no era nueva. Las instituciones religiosas habían dispersado mucho sus propiedades, como se puede ver en algunos de los libros de contabilidad que se han conservado. Citemos un par de ejemplos. Las rentas del convento de franciscanas menores observantes Corpus Cristi de Salamanca procedían de 29 lugares situados en una extensión de 65 por 45 kilómetros (mapa 8). Los agustinos canónigos regulares que dirigían el Colegio de Nues-

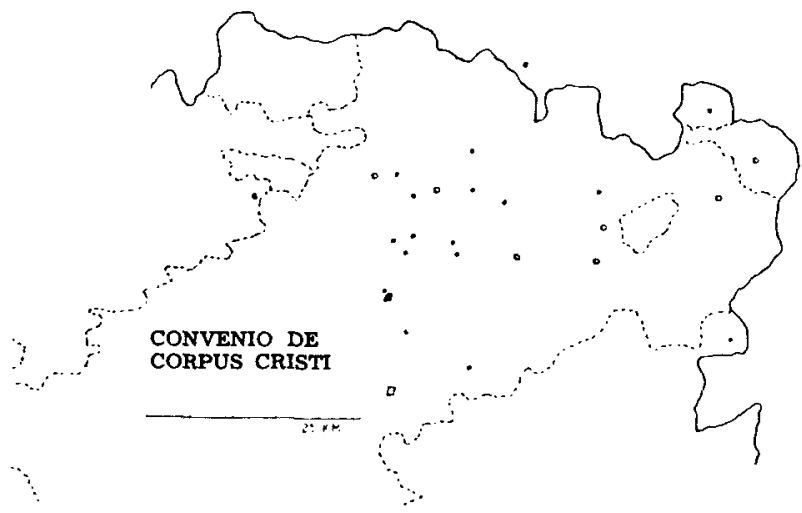

MAPA 8

tra Señora de la Vega recogían grano de campesinos de 23 lugares en una extensión de 55 por 30 kilómetros (mapa 9) (17).

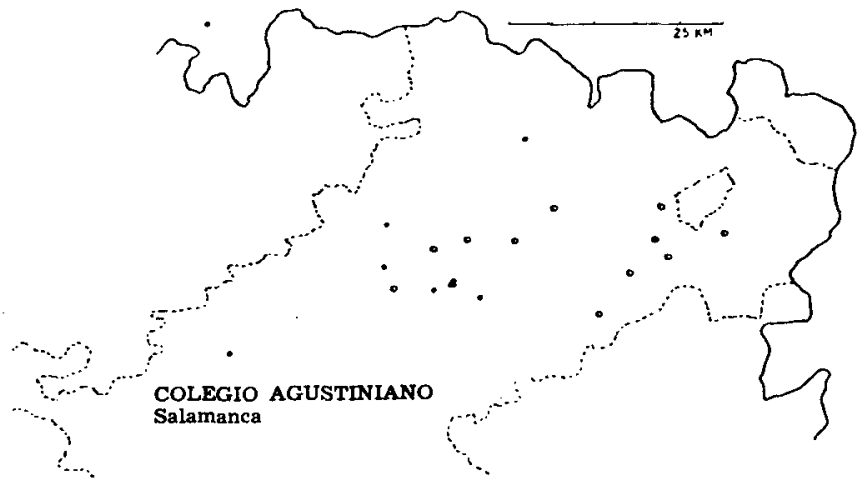

MAPA 9

(17) Archivo Histórico Nacional, Clero, Libro 10880, "Libro de granos de este conv.to de Corpus para...1800, 1801 y 1802..." y Libro 10653, "Receta de Rentas de Granos, Marabedis y Gallinas del Colegio de N.a S.ra de la Vega", 1805-1806. 
Es cierto que las fundaciones religiosas obtenían una gran parte de sus propiedades a través de donaciones y el azar podía determinar los sitios en los que las recibían. Sin embargo, los libros de contabilidad muestran que a veces compraban y vendían propiedades, por lo que sus fincas no eran algo absolutamente inmutable. También podían fomentar las donaciones que más les convenían. Tenían una clara preferencia por las propiedades que se podían arrendar a cambio de grano, ya que esta mercancía se podía consumir o vender fácilmente, pero no les importaba dónde estuvieran situadas. Los nuevos compradores seglares parece que heredaron su concepto de propiedad de los antiguos propietarios religiosos.

Puede que esta conducta parezca perversa. Las consideraciones económicas racionales parecerían prescribir la concentración de las propiedades similares o, al menos, complementarias, lo más cerca posible, para reducir los costes, como recomendaba el Rey a los propietarios de mayorazgos en el decreto citado al comienzo de este artículo. La mayoría de los nuevos compradores ignoraba esta consideración. Era la oportunidad, desde luego, la que determinaba, hasta cierto punto, lo que podían comprar, pero se ponían en venta tantas propiedades que podían escoger y elegir, como hizo Alonso y Moral. La explicación se encuentra no en la limitación y ni siquiera en la casualidad, sino en una motivación consciente. Su estrategia consistía en ocuparse directamente poco de la agricultura de sus tierras. No pretendía inspeccionar sus propiedades en persona o por medio de sus administradores, $o$, desde luego, no regularmente. Por el contrario, se daban por satisfechos con firmar contratos con arrendatarios que se hicieran cargo plenamente de lo que ocurriera en los campos y satisficieran los deseos de sus terratenientes pagando anualmente su renta, en especie o en moneda, en la fecha señalada. Miguel Artola sostiene correctamente que esa política era una decisión económica racional para los grandes terratenientes aristocráticos cuyas propiedades dispersas les obligaban a estar ausentes (18). Sin embargo, deduce que era la dispersión la que obligaba a los propietarios a obrar así. El ejemplo de los compradores de Salamanca indica que esa política era sabiduría aceptada y que era ella la que regía la creación de las fincas, tanto grandes como pequeñas, y no al revés. De hecho, Helen Nader ha descrito la forma en que los marqueses de Mondéjar se hicieron en el siglo xvi con una vasta red de propiedades de Castilla la Nueva y Granada, muy conscientes del potencial de cada adquisición (19).

En un pasaje clásico, Marc Bloch describió la forma en que el señor me-

(18) Artola, 49-51.

(19) Helen NADER, "Noble Income in Sixteenth-Century Castile: The Case of the Marquises of Mondéjar, 1480-1580", Economic History Review, 2." época, 30 (1977), 411-428. 
dieval francés, en el proceso de sustituir trabajo de sus siervos por renta, se transformó de directivo de un negocio, de empresario, si se quiere, en un «rentista del suelo" (20). Nuestros ricos compradores castellanos actuaban como los señores franceses de finales de la Edad Media, pero sería un,error ver solamente el pasado en su conducta. Muy al contrario, se pueden comparar con los inversores modernos que diversifican sus carteras para minimizar riesgos. La renta que recibían estos hombres apenas difería de los dividendos de acciones muy seguras. Mientras que la cosecha de un agricultor podía aumentar y disminuir, el rendimiento del propietario permanecía relativamente fijo, dependiendo principalmente de la estabilidad de los mercados de cereales. Los campesinos tenían que ir a Salamanca a firmar el arrendamiento y entregar la renta; los costes de transacción eran mínimos para el propietario. Su estrategia era la de los inversores, no la de los empresarios.

Sin embargo, la diversificación de las compras tenía sus límites. La ciudad de Salamanca era la capital de un gran partido que comprendía la mayor parte de las extensas llanuras del norte de la provincia. Las instituciones religiosas y la Universidad habían establecido un control económico en esta región y los nuevos compradores, salvo raras excepciones, se mantuvieron dentro de esa órbita. La administración política parece que fue un factor fundamental, junto con las redes de transporte y los mercados, en la determinación de la configuración de las diferentes regiones económicas. El registro de los contratos por parte de los notarios de la cabeza de partido, los casos judiciales, la administración de los tributos reales y actividades parecidas permitieron a las personas relacionadas con la propiedad agrícola y las finanzas familiarizarse con el territorio y la economía de su partido, pero mucho menos con los de fuera. Un estudio sobre el pequeño partido de El Mirón, situado en las sierras del sur de la provincia, muestra que allí casi todos los compradores eran campesinos. Estos traspasaron los límites de su término en sus adquisiciones, pero rara vez compraron fuera del partido (21).

La observación de la provincia de Jaén muestra elocuentemente los límites de la diversificación de las compras, pues en esta provincia también hubo grandes compradores, pero sus adquisiciones no fueron tan dispersas como las de los de Salamanca. Los pueblos eran pocos y relativamente grandes, sólo 74 en toda la provincia, y sus agricultores cultivaban tierras dentro de los límites municipales, que podían estar distribuidas ampliamente a través de los extensos términos. Su agricultura, especializada en trigo y aceite de oliva, estaba tan orientada hacia el mercado exterior, si no más, que la de Salamanca. Entre los mayores compradores de la provincia de Jaén (22), sólo

(20) Bloch, 100-101.

(21) Hoy forma parte del partido de Piedrahita, en la provincia de Avila.

(22) Los "mayores compradores" se refiere a los que gastaron mayores canti- 


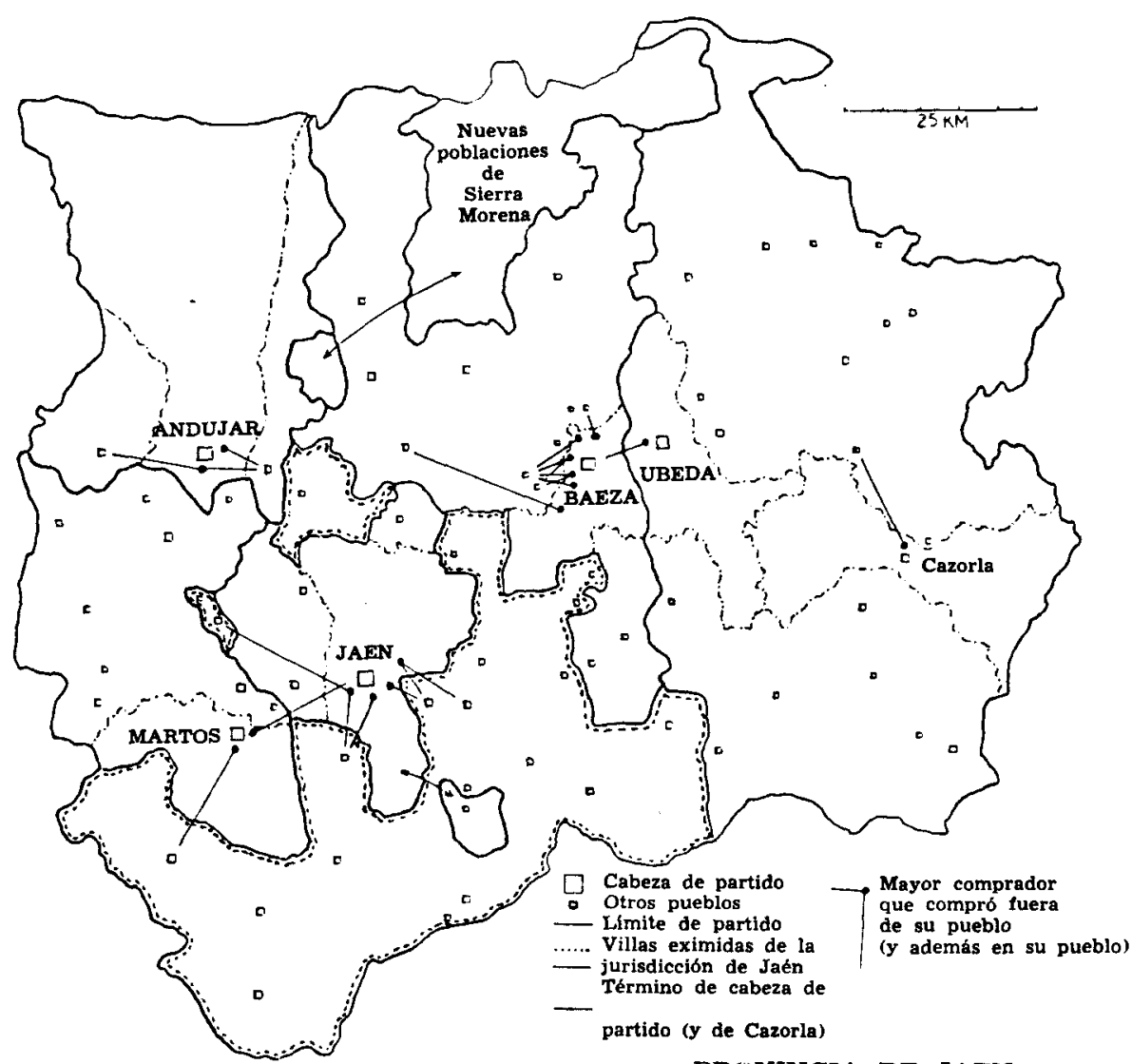

PROVINCIA DE JAEN

MAPA 10

uno de cada ocho compró en más de un término y casi todos los que lo hicieron adquirieron propiedades en pueblos adyacentes, centrándose generalmente en las cabezas de partido.

En otras palabras, la provincia de Jaén parece que estaba formada por una serie de pequeñas economías locales. Los pocos compradores que adquirieron tierras fuera de los límites de su término permanecieron dentro de estas economías locales (véase el mapa 10). El partido de Jaén no dominaba la provincia, como en Salamanca; aunque era grande, estaba formado, en gran parte, por las sierras situadas al sur de la ciudad. Los partidos de Baeza y Ubeda eran tan ricos o más que el de Jaén, la capital no hacía sombra a los demás pueblos de su provincia, como ocurría en el caso de Salamanca,

dades de dinero individualmente; en conjunto, gastaron la mitad de la cantidad total de todas las compras realizadas en la provincia. 
y la proporción de grandes compradores de la provincia que provenían de la capital era menor que en el caso de Salamanca. De nuevo, parece que la organización política desempeñó un claro papel en la formación de las pautas económicas.

Nos encontramos, pues, ante un interesante fenómeno. Los mayores terratenientes de España, los grandes, diversificaron sus propiedades a todo lo largo y ancho del país. En la desamortización de Carlos IV, hubo unos pocos compradores que vivian en Madrid que realizaron sus compras en las provincias de Salamanca y Jaén. Un caso parecido es el de don Martín de Ganá, el comerciante de Bilbao que compró ampliamente en Salamanca y se puede pensar que también en otras provincias. Estos compradores, que vivíarı en centros políticos y económicos, imitaban la pauta nacional de propiedad de los grandes, aunque en muy poca medida. En un segundo nivel se encuentran las grandes instituciones eclesiásticas que en el pasado habían ido acumulando propiedades en las provincias y partidos, y los residentes locales ricos que ahora operaban en la misma escala y adquirieron en la desamortización muchas de las propiedades de estas instituciones. Funcionaban dentro de órbitas económicas locales, con las que estaban familiarizados. Finalmente, en la provincia de Salamanca, pues la de Jaén tenía una estructura diferente, encontramos campesinos que cultivaban grupos de parcelas dispersas en sus pueblos y en otros cercanos. En la desamortización, algunos campesinos compraron pequeños grupos de parcelas, pero una vez más, dentro de las áreas con cuya agricultura estaban familiarizados.

Vemos, pues, que la dispersión de las propiedades se puede encontrar en todos los niveles económicos. Dado que fue tan ávidamente perseguida por los compradores en la desamortización a finales del siglo xviII, es difícil sostener que la dispersión de las fincas de los grandes o de los campesinos que existía desde hacía siglos se debiera a factores externos como el deseo de proteger las propiedades de las familias aristocráticas de los caprichos de un heredero imprevisor o de la subdivisión incontrolada entre los hijos de los campesinos. En cualquier caso, la subdivisión a través de la herencia de los campesinos es una explicación irrelevante en los pueblos de Salamanca, ya que casi toda la tierra pertenecía a personas de fuera desde hacía mucho tiempo. Una explicación más defendible es que la sociedad española del An. tiguo Régimen estaba impregnada de un saber popular que advertía a todo aquel que obtenía su renta de la tierra que no se lo jugara todo a una carta (23). El deseo de minimizar el riesgo que encuentra McCloskey en los

(23) Una carta de Plinio el Joven, escrita a finales del siglo I d.C., revela que la politica de distribuir las propiedades ampliamente puede que tenga un origen muy antiguo. Escribió: "Me han ofrecido una finca que es contigua a la mía $y$, de hecho, está entremezclada con ella. Son varias las circunstancias por las que me inclino a comprarla, pero hay otras, de no menor peso, que me lo 
campesinos de los pueblos ingleses de open field era en España un fenómeno general. Cuando los reformistas reales trataron de introducir el progreso en el campo, transformando las propiedades institucionales vinculadas en propiedad privada enajenable, este saber popular moldeó los resultados.

¿Significa esto que fue una mentalidad innata opuesta a la aventura empresarial la que impidió el crecimiento económico en España? La forma en que se llevó a cabo la desamortización eclesiástica y, más tarde, la civil, ha sido acusada regularmente del retraso del progreso económico. ¿Apoyan nuestros hallazgos esta acusación? Es tentador contestar afirmativamente. La introducción de nueva tecnología requiere tanto capital como una supervisión directa especializada, no el tipo de mentalidad de rentista del hombre trico del Antiguo Régimen. Uno recuerda el argumento de David Landes de que la Revolución Industrial llegó tarde a Francia porque sus inversores estaban más preocupados por proteger los ahorros de la familia que por aceptar un riesgo en nuevas formas de inversión (24). Sin embargo, la respuesta a si fue esta práctica la que frenó realmente el progreso económico español no es obvia. Una forma de responder es determinar la razón por la que los compradores españoles no trataron de concentrar las propiedades. Una posible explicación es que los reformistas españoles no consideraron que las grandes concentraciones de tierra eran económicamente beneficiosas. Sostenían la creencia, típica de la Ilustración, de que la explotación más eficiente era la finca familiar, no el latifundio, al que veían como una fuente de propiedad absentista. Jovellanos sostenía que liberar la tierra de las restricciones legales al comercio acabaría dando lugar a fincas familiares, ya que éstas eran más eficientes y el funcionamiento de las simples leyes económicas haría que la tierra se dedicara al uso más productivo (25).

Sin embargo, es improbable que el comprador medio, por muy rico que fuera, hubiera leído la teoría económica de la época. La conducta de los compradores se puede explicar más sencillamente por el hecho de que la concentración tenía pocas ventajas económicas que ofrecer. Los propietarios

desaconsejan. La primera ventaja que tiene es que uniendo ambas fincas tendré una buena propiedad; la segunda, la ventaja y el placer de poder visitarla con una sola molestia y un solo gasto; poder tenerla vigilada por un mismo administrador... Por otra parte, no sé si es prudente que una proporción tan grande de la propiedad esté expuesta a los mismos riesgos de clima y catástrofes (iisdem casibus); parece que distribuir las propiedades que uno tiene entre diferentes situaciones constituye un método más seguro de protegerse contra los caprichos de la fortuna..." Debo esta cita a William Hodges.

(24) David LANDEs, "French Entrepreneurship and Industrial Growth in the Nineteenth Century", Journal of Economic History, 9 (1949), 45-61.

(25) Informe de la Sociedad Económica de esta Corte al... Consejo de Castilla en el expediente de ley agraria, en Gaspar Melchor de Jovellanos, Obras publicadas e inéditas, t. 2 (Biblioteca de Autores Españoles, t. 50; Madrid, Rivadeneyra, 1859), 19-138, véase 84 . 
ingleses y los grandes agricultores arrendatarios deseaban los cerramientos porque la experiencia había demostrado que las rotaciones de nuevas cosechas y la mejora de la ganadería se podían introducir mejor en tierras cerradas que en campos abiertos. Aunque aquí tendría que ceder la palabra a economistas agrícolas más competentes que yo, esto no parece que fuera así en Salamanca a finales del siglo xvili, dado su clima. Lo que se podía hacer en esa época era roturar tierras incultas. Esta era una actividad que beneficiaba tanto a los campesinos como a los propietarios ausentes, y ambos la ejercieron activamente, especialmente en los despoblados, creando accidentalmente más, y no menos, parcelas dispersas. El proceso había comenzado antes y continuó después de la desamortización. En la segunda mitad de siglo, Jaén fue testigo de una rápida expansión de los olivares y una más lenta de las tierras de sembradura; ambos producían para el mercado exterior, y la desamortización permitió acelerar el proceso.

Aunque puede que la falta de espíritu empresarial no produjera efectos muy negativos en el desarrollo de la agricultura española al final del Antiguo Régimen, quizá no fuera así en períodos posteriores. La introducción de los ferrocarriles y la especialización más rápida de la agricultura para el mercado que llegaron en el siglo XIX iban a proporcionar mayores oportunidades a los propietarios con imaginación y decisión. Sin embargo, sería difícil imaginar que la mentalidad con la que se realizaron las operaciones de los grandes compradores de Salamanca bajo el reinado de Carlos IV iba a desaparecer de la noche a la mañana o ni siquiera en una o dos generaciones. Podía contribuir en buena medida a la lentitud para responder a los acontecimientos económicos que los observadores contemporáneos y los historiadores posteriores han adscrito a los terratenientes españoles del siglo XIX. Nicolás Sánchez-Albornoz ha analizado recientemente la manera en que los productores agrícolas de la meseta de Castilla la Vieja de este período cayeron en la trampa de producir un monocultivo de trigo, convirtiéndose así en una «colonia» de la periferia española (26). El deseo de obtener inversiones seguras en lugar de explotar el potencial no desarrollado, que caracterizó a la mentalidad que hemos descubierto, puede que fuera un importante factor en esta política descaminada.

Sin embargo, no debemos exagerar. Los efectos de la mentalidad de los compradores no fueron los mismos en todas partes. La estructura política y económica de Jaén hizo que, en la desamortización de Carlos IV, la mayoría de los compradores concentraran sus compras en un solo término, lo que les permitía vigilar su cultivo y responder a los cambios del mercado. Alonso y Moral mostró un espíritu empresarial parecido. Concentró sus compras,

(26) Nicolás SÁnchez-AlboRnoz, "Castilla en el siglo xIx: una involución económica", Revista de Occidente, 17 (1982), 35-49. 
indudablemente, con la idea de que podía reducir los costes de administración y, quizá, pensaba que podía explotar mejor los préstamos concedidos a los campesinos si tenía que tratar con menos pueblos, todos ellos situados en una región limitada. No proyectó ninguna mejora de las cosechas ni de las herramientas.

Por un irónico giro del destino, su estrategia iba a resultar menos ventajosa a largo plazo que la de los compradores que combinaron pequeñas parcelas con grandes términos redondos. La llegada del ferrocarril y otras mejoras del siglo XIX en la comercialización introdujo la especialización en la ganadería de los despoblados dirigida a la producción de carne para el mercado. Algunos de los herederos de los compradores que los habían adquirido participaron en el crecimiento económico, mostrando que ellos, al menos, sí tenían un cierto espíritu empresarial. La inversión de Alonso y Moral en grupos de pequeñas parcelas no fue retribuida con ningún potencial de crecimiento similar y dejaron de ser inversiones de primera calidad. Sus propietarios absentistas, carentes de una estrategia clara e ideas claras para mejorar su rentabilidad, las vendieron a lo largo del siglo. En 1900 la mayoría de las parcelas de open field estaban en manos de campesinos, que, sin orientación. continuaban explotándolas siguiendo las viejas prácticas (27). En nuestro siglo, los nuevos fertilizantes, los pozos artesianos y los tractores han revolu. cionado el campo de Salamanca; y el Gobierno de Franco concentró las pequeñas parcelas en explotaciones más aprovechables para la innovación tecnológica.

En Jaén la situación era más prometedora para el futuro, si no hubiera sido por un acontecimiento diferente que alejó a los propietarios del cuidado directo de sus propiedades. La evidencia muestra que durante el siglo xIX los principales habitantes de los pueblos andaluces emigraron a las capitales de provincia, donde podían mezclarse en la sociedad de sus iguales, educar y casar mejor a sus hijos y participar en la política (28). No obstante, la élite de Andalucía parece que ha sido económicamente más progresista que

(27) Angel Cabo Alonso, "La Armuña y su evolución económica", Revista Geográfica, feb. 1955, 73-137, y mayo 1955, 367-427; Angel Cabo Alonso, "Antecedentes históricos de las dehesas salmantinas", en Consejo Superior de Investigaciones Científicas, Estudio integrado y multidisciplinario de la dehesa salmantina, 1; Estudio fisiográfico descriptivo (Salamanca-Jaca, Centro de Edafología y Biología Aplicada de Salamanca y Centro Pirenaico de Biología Experimental, 1978).

(28) A. M. Bernal, "Formación y desarrollo de la burguesía agraria sevillana: caso concreto de Morón de la Frontera", La question de la "bourgeoisie", dans le mond hispanique au XIXe siècle: Colloque international organisé par l'Institut d'Etudes Ibériques et Ibéro-américaines de l'Université de Bordeaux III en Février 1970 (Bibliothéque de l'Ecole des Hautes Hispaniques, fascicule 45: Bordeaux, 1973), 47-89, y Richard Herr, "La élite terrateniente española en el siglo XIX", Cuadernos de Investigación Histórica, 2 (1978), 591-615, véase 597-598. 
la de Castilla la Vieja, y Jaén se ha convertido en el siglo $\mathrm{xx}$ probablemente en la región olivarera más rica del mundo.

La dispersión de las propiedades parece, pues, haber sido un rasgo de la agricultura del Antiguo Régimen en todos los niveles, desde los grandes hasta los campesinos. Se puede explicar en gran parte por el deseo de minimizar el riesgo, cubrir las apuestas y diversificar la cartera. También era demasiado ubicua, al menos en España, como para poder explicarla por el funcionamiento del mayorazgo o las prácticas hereditarias campesinas. Tenía sentido económico en un sistema agrícola relativamente estático, pero cuando el cambio comenzó a estar a la orden del día, dio lugar a una clase de terratenientes mal preparados para enfrentarse al resto de una economía que estaba modernizándose, muy distintos de los propietarios ingleses que llevaron a cabo el enclosure movement.

(Traducción: María Esther Rabasco y Luis To H ARIA) 